\title{
Changing Behavior With Normative Feedback Interventions: A Field Experiment on Curbside Recycling
}

\section{P. Wesley Schultz}

To cite this article: P. Wesley Schultz (1999) Changing Behavior With Normative Feedback Interventions: A Field Experiment on Curbside Recycling, Basic and Applied Social Psychology, 21:1, 25-36

To link to this article: Article Link (https://doi.org/10.1207/s15324834basp2101_3)

Published online: 07 Jun 2010.

Full Terms \& Conditions of access and use can be found at Copyright Information (http://www.tandfonline.com/action/journalInformation?journalCode=hbas20) 


\title{
Changing Behavior With Normative Feedback Interventions: A Field Experiment on Curbside Recycling
}

\author{
P. Wesley Schultz \\ Department of Psychology \\ Claremont Graduate University
}

This field experiment increased the frequency of curbside recycling among community residents using feedback interventions that targeted personal and social norms. M y team of re- searchers observed curbside recycling behaviors of 605 residents of single-family dwellings for 17 weeks. Groups of contiguous houses were randomly assigned to 1 of 5 experimental conditions: plea, plea plus information, plea plus neighborhood feedback, plea plus individual household feedback, or the control condition. Interventions were implemented using door hangers delivered to each household over a 4-week period. Results showed significant increases from baseline in the frequency of participation and total amount of recycled material for the individual (i.e., personal norm) and the group feedback (i.e., descriptive norm ) interventions. None of the interventions altered the amount of contamination observed. These findings are interpreted as consistent with recent research on personal and social norms and suggest a link between behavior change produced through norm activation and behavior change produced through feedback. Implications for research and public policy are discussed. 
Social psychologists have long been interested in change - change in attitudes and change in behaviors. To this end, a large body of research has attempted to develop effective strategies to produce change. One such strategy involves the activation of social norms. Norms are sets of beliefs about what other people are doing or what they approve or disapprove of doing (Cialdini, Reno, \& Kallgren, 1990). These norms help to guide hum an behavior and represent a potential target for interventions designed to change behavior. This article presents the results from a field experiment designed to activate social and personal norms through feedback in order to increase residential curbside recycling. We compared the results from normative feedback with a more traditional inform action-based intervention and present a cost-benefit analysis for the city-wide implementation of each intervention.

\section{RECYCLING IN THE UNITED STATES}

The disposal of solid waste is becoming both an environmental and economic burden. Disposing of trash in the United States currently costs approximately \$30 billion each year and is predicted to reach $\$ 75$ billion by the year 2000. In 1989 the U.S. Environmental Protection Agency (EPA ) announced a national goal of reducing landfill use. In the 8 years since this announcement, all 50 states have passed legislation requiring cities to reduce the amount of trash buried in landfills. Curbside recycling programs are the most commonly implemented strategy in this quest. Nationally, more than 8,000 curbside recycling programs serve more than 134 million people, and both numbers are growing rapidly (EPA , 1994). As a case in point, the number of curbside recycling program s in California grew 65\% between 1990 and 1994 (California Integrated Waste Management Board, 1995).

Recycling has the potential to divert thousands of tons of reusable materials away from landfills. However, many cities have found a ceiling to the effectiveness of their curbside recycling programs. Thus, recycling offers social psychologists both an opportunity to apply theoretically based interventions to help solve a pressing social problem and an excellent set of behaviors with which to test theories of behavior change. Applied social psychologists have been testing various behavioral interventions on recycling for 20 years. A recent review of findings concerning these interventions covered prom pts, public commitment, normative influence, goa l setting, removing barriers, rewards, and feedback (Schultz, Oskamp, \& Mainieri, 1995).

\section{USING INFORMATION, NORMS, AND FEEDBACK TO INCREASE RECYCLING BEHAVIOR}

The most commonly used and studied intervention to improve recycling is the dissemination of information (Schultz et al., 1995). Information strategies are intended to make people more know ledge able about recycling, which in turn is expected to lead to increased recycling. The implicit assumption behind this strategy is that if people knew more about recycling, they would act 
accordingly. However, results on the effectiveness of information interventions in improving recycling behaviors are mixed (Leeming, Dwyer, Porter, \& Cobern, 1993; Porter, Leeming, \& Dwyer, 1995). In general, the results from studies of information interventions typically show weak effects (Gardner \& Stern, 1996; Leeming et al., 1993). Despite this fact, so-called knowledge-deficit interventions are com m only used strategies to change behavior - in part because they are inexpensive and relatively easy to implement.

Although lack of know ledge can be an important barrier to action, motivation appears to be a more powerful determinant of who will and will not recycle. One potential source of motivation is social norms - sets of beliefs about the behavior of others. Cialdini et al. (1990) have distinguished be- tween descriptive and injunctive social norms. Descriptive norms are beliefs about what other people are doing; injunctive norms, in contrast, are beliefs about what other people think should be done; that is, injunctive norms are prescriptive. Personal norms - feelings of obligation to act in a particular manner in specific situations - are a second source of normative motivation. Schwartz and Fleishm an (1978) defined personal norms as "self-expectations for behavior backed by the anticipation of self-enhancement or [self-] deprecation” (p. 307). Personal norms differ from social norms in that they refer to internalized self-expectations, whereas social norms refer to the behavior of others. A substantial body of research suggests that norms help to determine behavior, particularly when they are activated (Cialdini et al. 1991; Reno, Cialdini, \& Kallgren, 1993; Schwartz \& Fleishman, 1978).

Activation involves making the norms salient in a particular setting. Researchers have developed a variety of approaches for the activation of norms, but one of the most practical is through the use of feedback. Feedback interventions are defined as "actions taken by (an) external agent(s) to provide information regarding some aspect(s) of one's task performance" (Kluger \& DeNisi, 1996, p. 255). The behavior change associated with feedback interventions is one possible response to a discrepancy between existing performance on a task and an abstract standard. The feedback produces a motivation to eliminate the feedback-standard disparity. The discrepancy can be rem oved in several ways, of which raising performance to the level of the standard is the desired resolution. However, the discrepancy can also be resolved by abandoning the standard, by changing the standard, or by rejecting the feedback message (Kluger \& DeNisi, 1996).

As Kluge $r$ and DeNisi (1996) pointed out, many possible standards exist against which the feedback is compared. Standards can be prior expectations, past performances, ideal goals, or social norms. Here, I focus on the use of social and personal norms as the standards in feedback interventions. Researchers have successfully used feedback as a way to in- crease desired behaviors in many different environmental arenas, including reducing home energy consumption, increasing gas mileage, decreasing heating fuel use, and reducing litter (Dixon, Knott, Roswell, \& Sheldon, 1992). Five studies have specifically assessed the effectiveness of feedback as an intervention to improve recycling, with mixed results (DeLeon \& Fuqua , 1995; De Young et al., 1995; Goldenhar \& Connell, 1991-1992; Hamad, Bettinger, Cooper, \& Semb, 1980-1981; Katzev \& Mishima, 1992). 
However, none of these studies directly attempted to activate norms through feedback, and no study has specifically examined feedback as a case of norm activation.

This study examined the effects of normative feedback on community curbside recycling. We predicted that activating personal and social norms would lead to an increase in household recycling. Second, we predicted that normative feedback would be more effective than disseminating factual information or making a plea to recycle. Two normative feedback interventions were developed: individual feedback and group feedback. These two feedback conditions differed in the type of norms they targeted, with the individual feedback condition being more personal and the group condition being more social (i.e., descriptive). Finally, we tested the hypothesis that behavior change would be more likely to occur for those households where the discrepancy between behavior and feedback was large.

\section{METHODOLOGY}

\section{Sample and Measurement}

Six hundred and five households in La Verne, California - a middle-class residential suburb of Los Angeles - participated in the study. During the study, La Verne had a community-wide voluntary curbside collection program for newspaper, glass, plastic, and metal. The program had been in place for about 3 years. When the program initially began, all households received several special recycling containers provided by the disposal company, which collected residential recyclables in colored plastic 12-gallon crates. Separate crates were used for newspapers, glass, and plastics (only those designated \#1 and \#2), and metal cans (aluminum and tin). Any material placed in the recycling crates other than those listed was considered contamination. Recyclables were collected weekly on Mondays, the same day as the trash col- lection, but by different trucks, starting around 6:00 a.m.

Households were selected using 1990 census data to represent high, medium, and low socioeconomic status (SES) areas based on property value (see also Oskamp, Burkhardt, Schultz, Hurin, \& Zelezny, 1998; Oskamp, Zelezny, Schultz, Hurin, \& Burkhardt, 1996). Approximately 200 contiguous homes from each SE S area were selected. After removing vacant houses from the sample and an additional 92 households that were part of an existing block-leader program, the study included 605 house s, all single-family dwellings.

Oskamp et al. (1998) observed the participation rate, amount of recyclables collected, and quality of recyclables at each household over an 8-week period, and examined the relation between these observed behaviors and self-report data obtained from a survey. These 8 weeks of observations were used as a baseline to com pare the effectiveness of the interventions in this study.

\section{Experimental Procedure}

Approximately 120 houses were randomly assigned to each of five experimental conditions: plea alone, plea plus individual written feedback, plea plus group written feedback, plea plus information, 
and control. Households were grouped by small contiguous areas ranging in size from 5 to 16 houses. This procedure grouped households geographic ally so that discussion between residents in different conditions would be minimized (to reduce the possible diffusion of the treatments), and we randomly assigned the small contiguous areas to experimental conditions such that each SES level was equally represented in each condition. In addition, experimental conditions were equated on their members' past recycling participation, as measured during the 8 weeks of unobtrusive observation. This assignment procedure produced five groups of approximately 120 households, each of which had an average participation baseline rate within $1 \%$ of each other.

Nine weeks elapsed between the concluding baseline observations and the pre-intervention observations for the intervention study. The week prior to beginning the interventions, all residents except those assigned to the control condition received a message stating that, "Volunteers will be conducting a study on recycling. Your household has been selected as part of a larger sample of La Verne residents. ... In order for La Verne to achieve the benefits of recycling, please try to recycle as much as possible." This information (the plea) was printed on one side of a green door hanger and placed on the front doorknob of each household in the four experimental conditions. Houses in the control condition did not receive the door hanger, and its delivery to the other 484 households required approximately $10 \mathrm{hr}$ of work. The plea served two purposes. First, it informed the households about the study - a necessary prelude to the other interventions - and second, it served as a manipulation in itself for the plea-only condition.

Beginning in the second week of the experiment, houses in the three experimental conditions (i.e., individual feedback, group feedback, information) received 4 weeks of information or feedback, presented on green door hangers on their front doorknob. We delivered the door hangers in the morning after the observers had completed the observations for all households in their area. Following that period, the interventions were discontinued, but observations continued for the following 4 weeks.

During the intervention period, participants in the individual feedback condition received 4 weeks of feedback about their recycling behaviors, delivered on the same day that materials were collected. The feedback informed each participant of the amount of each material collected at his or her house the previous week, the amount of each material collected the current week, and the total amount of each material collected for the duration of the study. We wrote the information on preprinted door hangers and delivered them 2 to $4 \mathrm{hr}$ after the observations were made.

Participants in the group feedback condition received a similar preprinted door hanger as the individual feedback condition for the same 4-week period, but with information about their residential area (i.e, the approximately 200 contiguous houses of their SES level). The feedback informed each participant about the amount of each material collected the previous week, the amount of each material collected the current week, the total amount of each material collected for the duration of the study, and the percentage of households that participated that week. Feedback was in the form of average participant behavior: average amount of material per week and average participation rate per week. 
Participants assigned to the information condition received four green door hangers for the 4week intervention, each with a different type of information. The first door hanger gave information about which materials were recyclable in the current La Verne recycling program . The second door hanger gave information about nonrecyclable materials and frequent contaminants. The third door hanger described the recycling process from collection to reuse of materials. The final door hanger presented information about energy and landfill conservation that results from recycling.

We used the control condition to eliminate possible seasonal trends in the data. We collected data for the baseline period in November and December, and we collected the intervention and postintervention data in March through May. Data comparisons with the control group ensured that changes in recycling behaviors were due to interventions, and not to seasonal trends.

\section{Observation Procedure}

Recycling behaviors were assessed through weekly observations of all selected households. The observers were trained graduate students who assisted in data collection as a part of their research team activities. Each week of observations required approximately 6 to 10 person-hr of work. We recorded participation, quantity of each material, and contamination of recyclables for each household. We coded participation as either yes or no for each week. We estimated quantity of recyclables as the number of quarter bins observed for each material (up to one fourth $=1$; full $=4$; two full bins = maximum score of 8). If any inappropriate material was observed in the recycling bins, we scored contamination as present.

To check the reliability of the observers, we computed interrater reliabilities. On three separate occasions, once for each S ES level, a pair of observers made observations for both their and another observer's areas. For participation, reliability (percentage of agreement) was $99 \%(\mathrm{k}=.97, p$ $<.001$ ). Reliability on the measure of contamination, calculated as the percentage of times the two observers agreed on the presence or absence of contamination in a recycling bin, was $87 \%(\mathrm{k}=.73, p$ $<.001)$. The interrater reliability for the amount of material recycled, averaged across the materials (i.e., glass, plastic, metal, and newspaper) and based only on those households that participated for that particular week, was assessed with a correlation coefficient between the two observers (average $r=.96$ ).

\section{Measurement of Dependent Variables}

To simplify the analysis, the 17 weeks of observations were divided into four time periods. I averaged the first 8 weeks of observations to produce baseline assessments for each of the three dependent variables. The first week of observations conducted when the plea was delivered, prior to the interventions, is considered a unique time period and is referred to as the preintervention period. I averaged the 4 weeks of observations conducted during the interventions to produce single measures of the dependent variables. Finally, the 4 weeks of postintervention observations were averaged to produce single assessments of the delayed effectiveness of the interventions on each of the 
dependent variables.

Because each observer later delivered the intervention in- formation to the same households that they had observed, they were not blind to the experimental condition. However, the weekly code sheets did not include the experimental condition for each household, the small groups of house $\mathrm{s}$ in the various conditions were intermixed, and the observers stated that they could not remember which households were in each condition during their observations.

Prior to testing the hypotheses, I computed the relation between the three dependent variables. The analysis revealed a high relation between participation and amount of recycling ( $r=.89$ ), participation and contamination $(r=.50)$, and contamination and amount $(r=.53)$ over the 8-week baseline observations. ${ }^{1}$ A new index of contamination per participation occasion was calculated by dividing the number of times we observed the resident contaminate the material for recycling in each observation period by the number of times he or she participated, showing the proportion of occasions on which contamination was observed. If the resident did not participate at least once during the period, I exclude $d$ him or her from the analysis of contamination per participation. Because contamination on any given occasion was a dichotomous variable, unlike total amount of material collected, total contamination was not a meaningful variable and was not analyzed.

These computations produced a total of three dependent variables: frequency of participation in the recycling program, total amount recycled, and proportion of contaminated bins.

\section{RESULTS}

The first set of analyses were conducted to determine if any changes occurred in the dependent variables prior to the implementation of the interventions. I calculated three dependent-sample $t$ tests to test for differences between average baseline scores (Weeks 1-8) and the pretest week prior to the initiation of the recycling interventions. To com pen- sate for the increased probability of making a Type I error due to multiple comparisons, A Bonferonni procedure was used to modify the critical alpha level to $.017(\alpha / 3)$. For participation, $t(604)=0.83, p=.63$, and amount, $t(604)=1.12, p=.42$, I observed no significant changes between the observation periods. However, for contamination, I found a significant increase, $t(514)=2.98, p<.017$. Because of the increase, I based subsequent analyses of the contamination variable on a withinparticipant analysis that exclude $s$ the baseline observations.

Following are the results from the analyses of each dependent variable. Table 1 presents the

${ }^{1}$ Because of the strong correlation between frequency of participation and amount of material recycled, a new index was calculated in which the amount of material recycled was divided by the frequency of participation. Results from analyses of this new index are not reported, but readers should note that the findings were similar to those found for amount of material and frequency of participation. 
means, standard deviations, and sample sizes for each measure of recycling within each experimental condition.

TABLE 1

Means, Standard Deviations, and Sample Sizes for Each Dependent Variable by Experimental Condition Across Time

\begin{tabular}{|c|c|c|c|c|c|c|c|c|c|}
\hline \multirow[b]{2}{*}{ Condition } & \multicolumn{3}{|c|}{$\begin{array}{l}\text { Average } \\
\text { Participation }\end{array}$} & \multicolumn{3}{|c|}{$\begin{array}{l}\text { Average Amount of } \\
\text { Material }\end{array}$} & \multicolumn{3}{|c|}{$\begin{array}{l}\text { Contamination/ } \\
\text { Participation }\end{array}$} \\
\hline & $o b 1$ & $o b 2$ & ob3 & $o b 1$ & $o b 2$ & $o b 3$ & $o b 1^{a}$ & $o b 2$ & ob3 \\
\hline \multicolumn{10}{|l|}{$\begin{array}{l}\text { Individual } \\
\text { feedback }\end{array}$} \\
\hline$M$ & .43 & .50 & 49 & .47 & .59 & .58 & .18 & .22 & .24 \\
\hline$S D$ & .37 & .36 & 37 & .45 & .50 & .49 & .27 & .34 & 36 \\
\hline$N$ & 118 & & & 118 & & & 103 & & \\
\hline \multicolumn{10}{|c|}{ Group feedback } \\
\hline$M$ & .42 & .46 & 50 & .48 & .56 & .58 & .16 & .18 & .17 \\
\hline$S D$ & .37 & .39 & 37 & .47 & .56 & .52 & .26 & .32 & .32 \\
\hline$N$ & 119 & & & 119 & & & 109 & & \\
\hline \multicolumn{10}{|c|}{ Information } \\
\hline$M$ & .42 & .45 & 46 & .51 & .58 & .56 & .19 & .22 & .18 \\
\hline$S D$ & .36 & .36 & 36 & .47 & .50 & .50 & .28 & .36 & .31 \\
\hline$N$ & 125 & & & 124 & & & 109 & & \\
\hline \multicolumn{10}{|l|}{ Plea only } \\
\hline$M$ & .42 & .42 & 46 & .49 & .51 & .56 & .21 & .24 & .25 \\
\hline$S D$ & .34 & .37 & 38 & .44 & .51 & .53 & .30 & .36 & .35 \\
\hline$N$ & 122 & & & 122 & & & 101 & & \\
\hline \multicolumn{10}{|l|}{ Control } \\
\hline $\begin{array}{l}M \\
\end{array}$ & .42 & .42 & 44 & .47 & .49 & .49 & .15 & .20 & .21 \\
\hline$S D$ & .35 & .39 & 39 & .45 & .49 & .49 & .25 & .35 & 36 \\
\hline$N$ & 121 & & & 121 & & & 98 & & \\
\hline
\end{tabular}

Note. ob1 = baseline period; ob2 = intervention period; ob3 = follow-up period.

${ }^{a}$ Analyses revealed a significant change in contamination during the 9 weeks that separated the baseline observation time period from the preintervention observation period. Because of this change, the baseline observations of contamination were not analyzed; they are reported here for descriptive purposes only. 


\section{Participation}

The first variable analyzed was the average weekly frequency of participation, testing for changes in the frequency of participation under each condition. The mixed-model analysis of variance (ANOVA ) contained one within-participant variable (time) with three levels (baseline, intervention, follow-up), and one between-participant variable (condition) with five levels. The analysis revealed a significant increase across time, $F(2,1200)=9.34, p<.01$, but not a significant condition effect, $F(4,600)=0.37, p>.05$. The interaction between time and condition was not significant, $F(8,1200)=1.21, p>.05$. However, given that only one of the experimental groups was a control condition, the overall increase across time and the nonsignificant omnibus interaction are not surprising.

To examine the effects of each experimental intervention relative to the control condition, I calculated four simple interactions, one for each intervention versus the control across time (baseline, intervention, postintervention). Because of the 9-week gap between the baseline and intervention observation periods, an analysis of trends is not appropriate. Instead, I made a series of simple interactions and single-degree-of-freedom comparisons. I followed significant interactions with planned comparisons for each intervention from baseline to intervention, and from baseline to postintervention.

The simple interactions for participation found a marginally significant effect for individual feedback, $F(2,474)=2.43, p<.10$, and a significant effect for group feedback, $F(2,476)=$ 3.34, $p<.05$. The information, $F(2,488)=1.04, p>.05$, and plea-only, $F(1,482)=0.32, p$ $>.05$, interactions were not significant. Planned comparisons indicated that the individual feedback condition increased significantly from baseline to intervention, $F(1,117)=7.23, p$ $<.001$. None of the other conditions were significantly different from baseline at the intervention time period. At the postintervention time period, both individual feedback, $F(1$, $117)=6.30, p<.01$, and group feedback, $F(1,118)=9.44, p<.01$, differed significantly from baseline. Figure 1 presents average weekly participation for each condition across the three periods.

\section{Amount of Material}

The amount of material recycled by each household was the second dependent variable analyzed. The measure analyzed was the average amount of material per week recycled by the residents (adding together the various materials, expressed as proportions of a crate). I conducted a mixedmodel (condition, time) ANOV A to assess the overall effectiveness of the interventions. This analysis revealed a significant increase across time, $F(2,1200)=13.58, p<.001$. Neither the condition main effect, $F(4,600)=0.44, p>.05$, nor the time by condition interaction, $F(8,1200)=$ $1.23, p>.05$, was significant. Again, these results were not unexpected given the design of the study. 


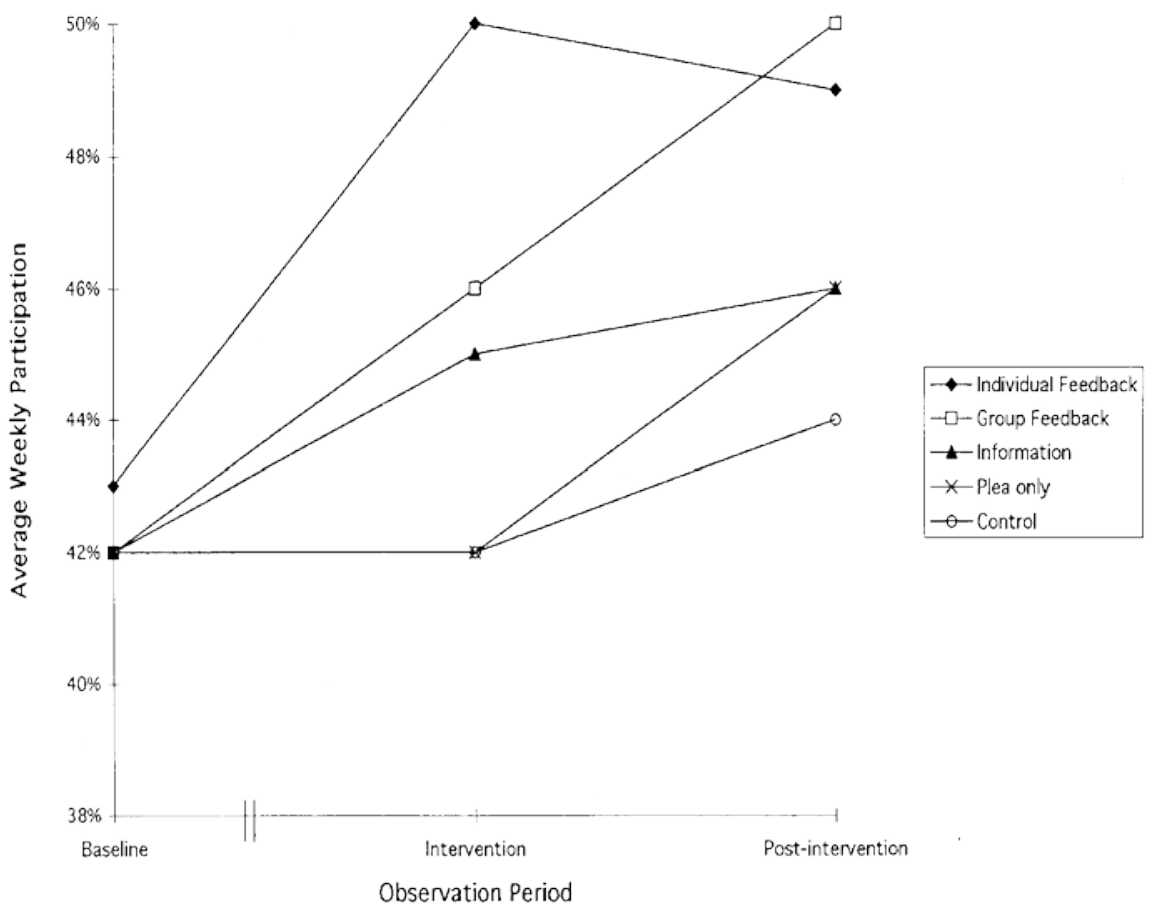

FIGURE 1. Average participation per condition.

I tested four 3 (Baseline, Intervention, Postintervention) $\times 2$ (Intervention, Control) simple interactions - one for each intervention. The se analyses showed a significant effect for individual feedback, $F(2,474)=5.38, p<.05$, and a significant effect for group feedback, $F(2$, $476)=3.01, p<.05$. The effects for information, $F(2,488)=0.82, p>.05$, and plea only, $F(2$, $482)=1.02, p>.05$, were not significant. Planned comparisons showed that the individual feedback condition, $F(1,117)=17.81, p<.001$, and group feedback condition, $F(1,118)=$ $13.32, p<.001$, increased significantly from the baseline to the intervention time period. Planned comparisons at the postintervention period showed that the increase remained statistically different from baseline during the postintervention observation period for both the individual, $F(1,117)=15.29, p<.001$, and group feedback, $F(1,118)=$ 13.03, $p<.001$, conditions.

\section{Contamination}

The level of contamination for each household was the final dependent variable analyzed. As described earlier, the mea- sure of contamination increased significantly during the 9 weeks that separated the baseline observations from the intervention observations. Because of this change, I excluded baseline observations from the analysis. I conducted a 5 (Condition) $\times 2$ (Intervention, Postintervention) mixed- model ANOVA, the results of which showed a nonsignificant main effect for condition, $F(4,515)=0.84, p>.05$; a nonsignificant time effect, $F(1,515)=0.10, p>.05$; and a nonsignificant two-way interaction, $F(8,515)=1.50, p$ 
$>.05$.

I calculated four simple interactions to test each intervention against the control condition at the intervention and postintervention periods. These analyses revealed no significant effects: individual feedback, $F(1,199)=0.42, p>.05$; group feedback, $F(1,205)=0.30 ; p>.05$; information, $F(1$, $205)=1.56, p>.05$; and plea only, $F(1,197)=0.15, p>.05$.

\section{Feedback—Standard Discrepancy and Behavior Change}

To this point, the results have shown a significant increase in the frequency of participation and amount of material recycled for the two feedback interventions, but not for information or plea only. Based on past research, we hypothesized that the feedback interventions would be more effective among residents for whom the feedback was more discrepant from past behavior. In essence, the feedback the researchers provided activated a norm (either social or personal) and the degree of this discrepancy should be directly related to the amount and direction of behavior change. Because the feedback delivered to the residents did not target contamination, we analyzed only participation and amount of material.

To test this hypothesis, I calculated two ANOVAs (one for participation and one for amount of material recycled). In these analyses, I used baseline scores as a continuous independent variable along with the categorical experimental condition (individual feedback, group feedback, control). The two dependent variables were the average participation rate and the average amount of material recycled across the 4-week intervention period - the period of time during which the norms were experimentally activated. Because of the continuous independent variable, I performed the ANOV A model calculations using multiple regression (see Keppel \& Zedeck, 1989; Pedhazur, 1997). The multiple regression and correlation (MRC) approach provides a more general analytic procedure with which to assess experimental data. The procedure involve s calculating vectors to code each of the in- dependent variables and interactions. In this analysis, I generated two vector codes for the condition main effect $(d f=2)$, and two vector code $s$ for the condition by baseline interaction $(d f=2)$. I entered these vector codes, along with the continuous baseline measure, as blocks into a regression analysis in the following order: the two vectors for condition, the continuous baseline measure, the two vectors coding the base- line by condition interaction.

The results for frequency of participation were consistent with the behavior-discrepancy prediction. The condition effect failed to reach statistical significance, $F(2,355)=1.21, p$ $>.05$; the baseline effect was highly significant, $F(1,354)=594.42, p<.001$, and the predicted two-way interaction was significant, $F(2,352)=3.66, p<.05$. For presentation purposes, I split the baseline measure of participation into the top 33\% and bottom 33\% , and I calculated the frequency of participation during the 4-week intervention period separately for these two groups of participants. As shown in Table 2, the bottom one third (i.e., low baseline rate of recycling) of the participants in the persona l feedback condition increased their participation rate from $5 \%$ during the baseline period to $24 \%$ during the intervention period; the group feedback condition increased from 5\% to $13 \%$; and the control condition increased from $5 \%$ to $6 \%$. The top one third of the participants (i.e., high baseline recyclers) in the personal feedback condition decreased from $85 \%$ to $79 \%$, and the top one third of the group feedback condition 
decreased from $86 \%$ to $84 \%$. The control condition increased slightly from $82 \%$ to $83 \%$.

The results for amount of material recycled showed a similar, though weaker, pattern of results. I used the same analytic procedure (Condition $\times$ Baseline ANOVA model calculated through MRC) to test the behavior discrepancy hypothesis. Results revealed a nonsignficant condition effect, $F(2$, $355)=1.02, p>.05$; a highly significant baseline effect, $F(1,354)=500.76, p<.001$; and a nonsignificant interaction, $F(2,352)=1.55, p>.05$. The average amount of material for the top one third and bottom one third during the baseline measure, separated for the individual feedback, group feedback, and control conditions, are shown in Table 2.

\section{DISCUSSION}

Results from this study indicate that normative feedback interventions can be an effective way to improve curbside recycling. First, both individual and group feedback increased the amount of material recycled as well as the frequency of participation. No significant changes were found for the information or plea conditions. None of the interventions significantly reduced the amount of contamination observed in the recycling bins. Finally, analyses of the discrepancy between behavior and feedback indicated that participants used the feedback to regulate their behaviorespecially their rate of participation.

The number of recycling programs around the United States (and internationally) has grown tremendously in the past 5 years and evidence show $\mathrm{s}$ that recycling is becoming a normative behavior (De Young, 1990). The finding that both group feedback and individual feedback increased recycling is consistent with recent research on normative behavior (Cialdini et al., 1990; Reno et al., 1993). Results from several recent studies on littering have demonstrated that mode ling a behavior (e.g., littering) that targeted either a descriptive or an injunctive norm successfully reduced the percentage of people who littered (Cialdini, Kallgren, \& Reno, 1991).

The research on normative behavior provides an explanation for the results obtained in this study. Because recycling is currently a socially desirable behavior, providing people with information about their recycling, as was done in the individual feedback condition, maybe activating persona 1 norms. This message puts pressure on the residents to act in accordance with the norm and put their recycling bin at the curb each week, even if their bin is not full. As anecdotal evidence, a resident told one of the observers in the study in the individual feedback condition, "You make me feel guilty for not participating." Individual household feedback provided information about the residents' recycling behavior, and no reference was made to other residents' behavior. 
TABLE 2

Frequency of Participation and Amount of Recycling Material for Feedback and Control Conditions Among Households High and Low in Baseline Recycling Behavior

\begin{tabular}{|l|l|l|l|c|}
\hline & \multicolumn{2}{|c|}{ High Baseline } & \multicolumn{2}{c|}{ Low Baseline } \\
\hline Characteristic & Baseline & Intervention & Baseline & Intervention \\
\hline $\begin{array}{l}\text { Frequency of } \\
\text { participation } \\
\text { Individual feedback }\end{array}$ & 0.85 & 0.79 & 0.05 & 0.24 \\
\hline$N$ & 37 & & & \\
\hline Group feedback & 0.86 & 0.84 & 0.05 & 0.13 \\
\hline$N$ & 37 & & 37 & \\
\hline Control & 0.83 & 0.83 & 0.05 & 0.06 \\
\hline$N$ & 30 & & 41 & \\
\hline $\begin{array}{l}\text { Amount of recycled } \\
\text { material }\end{array}$ & & & & \\
\hline Individual feedback & 1.23 & 1.33 & 0.01 & 0.29 \\
\hline$N$ & 26 & & 29 & \\
\hline Group feedback & 1.13 & 1.26 & 0.01 & 0.12 \\
\hline$N$ & 33 & & 30 & \\
\hline Control & 1.19 & 1.05 & 0.01 & 0.03 \\
\hline$N$ & 31 & & 28 & \\
\hline
\end{tabular}

In contrast, the group feedback intervention provided information about the recycling behavior of neighbors. This information may have not only activated the norms, but actually defined the norm ; that is, the information about the behavior of others distribute $d$ through the weekly door hangers provided the most accurate evidence available on which to base descriptive norms, and community residents $\mathrm{m}$ ay have used this in- formation to create a behavioral standard.

If norms are the causal agent in the effectiveness of the feedback interventions, individual feedback maybe effective only while the feedback is being given, whereas group feedback might provide a template for comparing current and future behavior. Thus, when the individual feedback stops, residents may quickly assume they are no longer being watched and revert to original behavior patterns. However, residents in the group feedback condition would still have a referent against which to com pare their behavior. This might produce longer lasting changes in behavior (as long as the referent group had at least a moderate level of recycling). The results 
from this study provide some suggestive evidence of this effect. Frequency of participation increased significantly from baseline to intervention period for the individual feedback condition, but the change was only marginally significant for the group feedback condition. However, the group feedback condition continue $d$ to increase from the intervention to the postintervention, and behavior change in the individual feedback condition leveled off.

Reno et al. (1993) suggested that activating injunctive social norms tends to produce a more generalized and longer lasting change in behavior than does activating descriptive norms. For example, activating injunctive norms will lead people to recycle in other settings (e.g., work, travel, vacation), or to abstain from littering in different contexts. However, our results suggest that descriptive norms may also produce a long-term (and perhaps more generalizable) change in behavior if the norms are defined and not just activated. If the feedback provides information that a behavior such as recycling is normative, then it provides a template against which future behavior can be compared. If, instead, the descriptive norms are made salient but not explicitly provided (as in the studies by Reno et al.), then the behavior change maybe short lived and context dependent. As a case in point, researchers developing school-based drug-prevention program s have found that providing children with information that drinking, smoking, and drug use is not normative can effectively reduce substance use (Donaldson, 1995; Donaldson, Graham, Piccinin, \& Hansen, 1995).

An alternative explanation for the slower but steady change in participation for the group feedback condition is based on the different processes involved in activating personal and descriptive norms. Personal norms maybe easier and quicker to activate than social norms. That is, the individual feedback condition was activating a personal recycling norm that already existed; we were not creating a new norm. In contrast, the descriptive norm $m$ ay have been created through our dissemination of information about the behavior of others. Thus, the process of internalizing and acting on a new social norm $m$ ay have required longer than the activation of an existing persona 1 norm .

In itself, the frequency of participation is not as important as the amount of material recycled because it does not directly entail the diversion of more material from landfills nor the conservation of more natural resources. In this sense, the frequency of participation is important only to the extent to which it generates more recyclable material. Analysis of the amount of material recycled 
found results similar to those obtained for the frequency of participation: Individual feedback and group feedback conditions increased the total amount of material, and the information, plea, and control conditions did not show a significant change.

The final variable measured in this study was contamination. The quality of the materials collected is directly related to the monetary value of the material and inversely related to the amount of effort required to sort the material. In fact, highly contaminated recyclables are often sent to landfills. Results from this variable were disappointing because none of the experimental interventions significantly affected the amount of contamination.

One possible explanation for this finding is limitations in the measuring contamination. To code contamination accurately, observers had to know what material could and could not be recycled and had to look carefully for improper materials in the bins. Over the course of the study, the observers $\mathrm{m}$ ay have become more know ledge able and more thorough in their observations. Thus, all conditions, including the control, showed an increase in the observed amount of contamination between baseline and preintervention. This finding necessarily reduced the analysis from a withinparticipant examination of change over time to a less powerful between-subjects design comparing each intervention against the control.

Behavioral feedback is effective only when it is discrepant from a "behavioral standard.” As Kluger and DeNisi (1996) have pointed out, m any possible standards exist against which the feedback can be compared. Standards can be prior expectations, past performances, ideal goals, or social norms. However, all of these standards are normative beliefs. Prior expectations are formed from interactions with others, past performances are only motivating if the person values consistency, ideal goals are similar to persona 1 norms, and social norms refer to beliefs about the behavior of others. In essence, feedback is effective when it activates a discrepancy between behavior and normative beliefs.

The results from the study showed that this behavior-standard discrepancy can either increase or decrease the targeted behavior. Residents initially low in recycling in- creased substantially following the normative feedback interventions. In contrast, residents initially high in recycling showed only a small increase in the amount of material recycled, and in fact actually decreased in frequency of participation. These findings are consistent with 
theories about responses to behavior-standard discrepancies (e.g. Kluge r \& DeNisi, 1996; Loc ke \& Latham, 1990). Larger discrepancies produce a stronger motivation for change, and comparing the standard with the feedback often generates a feedback sign, which determines the direction of the relation. For residents originally high in frequency of participation, this feedback sign was negative; for residents originally low in recycling, this feedback sign was positive.

Although this explanation is consistent with previous theoretical work on feedback, I need to address two alternative explanations. First, the feedbackdiscrepancy effects may have been produced by regression to the mean. Over time, scores tend to fluctuate toward the average. Because this study was conducted over 17 weeks, feedback signs possibly could have been produced by this regression tendency. However, a comparison of the effect sizes for the high and low baseline recyclers in the control group suggests that the results were not due to regression to the mean. If the behavior change was not produced by the feedback, then similar changes should have been observed for the control condition that did not receive the feedback. However, a comparison of the high and low baseline scores in the control condition revealed no such trend.

An alternate explanation is a possible ceiling effect. Residents in the high baseline recycling group were participating at an average of $85 \%$ each week, and residents in the low condition were recycling at an average rate of $5 \%$ each week. Generating increases in participation for a group that is al- ready recycling at an extremely high rate is difficult, and a lack of change could be due to this ceiling. However, the personal feedback condition and the group feedback condition decreased in participation, and the control condition remained unchanged. If the feedback was not used as a standard against which to judge behavior, the two normative intervention conditions should have remained stable across the two time periods - as was observed for the control condition. Before discussing the implications of these findings, one caveat is in order. As a practical way of preparing participants for the interventions, each experimental condition received the initial plea to recycle. Therefore, differentiating between the effects due to the plea and the effects due to the interventions alone is difficult. However, the lack of significant increases for the plea-only condition on any of the three dependent variables and the differential effects for the two feedback conditions suggest that the effects 
were not due to the plea alone. The need for an appeal before beginning other interventions is a technic al limitation of this design (and most experimental studies of recycling). However, this limitation does not render the results from this study inapplicable. Instead, it suggests that the effects observed in the study for feedback and information are either due to intervention alone or to the combination of plea and intervention. Either way, the results have clear implications for public policy regarding community recycling programs.

\section{Policy Implications}

A remaining question is the practical importance of the observed increases in the total amount of recycled material. Prior to implementing the interventions, residents in the individual feedback, group feedback, and plea-only conditions recycled an average of $0.47,0.48$, and 0.49 bins of material, respectively, each week. In the postintervention period, these three conditions recycled an average of $0.58,0.58$, and 0.56 bins of material weekly. Because the recycling bins held approximately 12 gallons, this translates into an increase of 1.28, 1.13, and 0.88 gallons per week, respectively - an increase of 23, 19, and 15\% , respectively, from baseline observations.

Any research on recycling has implications for the policies that determine how recycling programs are implemented. State and federal officials are pressuring cities to reduce the amount of refuse sent to landfills. In response, cities and waste disposal companies are trying to find ways to make recycling more effective. They want to know which intervention, or set of interventions, produces the best results. However, the answer to which is the best method depends on the desired outcome. Any of the three dependent variables might be viewed as the target variable, depending on the needs of the program.

Future research should be able to generate estimates of effect sizes for different types of interventions. Assuming that no moderator variables were operating, the ability of each intervention to affect each of the dependent variables could be estimated. Such an approach would determine which intervention would be effective at altering which aspects of recycling. Based on the findings herein, increasing the amount of material diverted from landfills can best be achieved by providing feedback. Individual feedback 
(i.e., personal norms) increased the amount of recycled material by $23 \%$, group feedback (i.e., descriptive norms) by $19 \%$, plea only by $15 \%(n s)$, and information by $11 \%(n s)$. On a citywide basis, a $23 \%$ increase in the effectiveness of the recycling program could be an important step toward meeting state mandates.

\section{Cost—Benefit Assessment}

In evaluating the usefulness of recycling interventions, one often overlooked consideration is the relative costs of the changes in behavior. It is well known that curbside recycling programs do not pay; that is, the money generated from the value of the collected materials does not usually cover all the costs of collection, processing, and administering the program. However, the cost of recycling maybe less than trash disposal, so interventions within these programs maybe cost effective. The following sections present a rough assessment of the costs and benefits of each of the four interventions used herein. This assessment is based on changes in the amount of material collected for each of the four interventions and on the effect size estimates provided previously. Using 1990 census data, the population of La Verne was estimated at 31,849 , and the number of households served by the recycling program in 1993 was approximately 8,000.

Costs. F or the plea-only, feedback, and information interventions studied, costs were incurred for materials (door hangers), labor (observation and dissemination), and planning (organization and scheduling). The door hangers used to disseminate the interventions cost approximately $2.5 \$$ each, including both the material and printing costs. Labor time to distribute the interventions required approximately $1.5 \mathrm{hr}$ for each 100 households. Similarly, the weekly observations that were required for the feedback interventions required approximately $1.5 \mathrm{hr}$ per 100 households. Finally, preparation of intervention materials required approximately $1 \mathrm{hr}$ per 100 households for the personal feedback, and $0.5 \mathrm{hr}$ per 100 households for the group feedback.

Using these figures, intervention materials would cost approximately \$25 per 1,000 households per week. However, labor costs would differ 
substantially with the individual feedback condition requiring approximately $40 \mathrm{hr}$ of labor per 1,000 households, $35 \mathrm{hr}$ for group feedback,15 hr for information, and $15 \mathrm{hr}$ for plea only. Estimating labor costs at minimum wage (\$5/hour) generates weekly labor costs per 1,000 households of \$200 for the individual feedback condition, \$175 for group feedback, \$75 for information, and $\$ 75$ for plea only. Combining materials and labor, the individual feedback, group feedback, information, and plea-only interventions would cost approximately $\$ 225, \$ 200, \$ 100$, and $\$ 100$, respectively, per week for 1,000 households . On a city- wide basis, the intervention costs for the approximately 8,000 households served by the recycling program would be $\$ 1,800$ per week for the personal feedback, $\$ 1,600$ for the group feedback condition, and $\$ 800$ for the information and plea-only interventions.

Benefits. The benefits of recycling are both environmental and economic. The environmental benefits of reduced landfill space, less pollution from collecting and processing raw materials, and conservation of natural resources are difficult to estimate, as are the long-term economic benefits of conservation. However, we can estimate the short-term revenues from the recycling interventions. These short-term revenues come from two sources: reductions in solid waste sent to landfills and funds received for the value of recycled materials. Typically, cities do not pay for the disposal of recyclables, and they often receive rebates for the value of the recyclables, which are applied to- ward the costs of collecting and processing the materials. The value of recyclables is largely dependent on the type of material, which fluctuates with supply and demand. In $1993 \mathrm{~L}$ a Verne received a credit of approximately $\$ 100,000$ for the value of the materials. Thus, the value of the increase in materials recycled (Percentage Increase $\times$ $\$ 100,000$ ) would equal $\$ 23,000$ for the individual feedback condition, $\$ 19,000$ for group feedback, $\$ 15,000$ for plea only, and $\$ 11,000$ for the information condition.

The second direct economic benefit from recycling is a reduction in the amount of solid waste sent to landfills and in the fees that are paid for each ton of trash that is dumped. These fees range widely, depending on the area, but in L a Verne they were estimated at $\$ 15$ per ton for 1993, which is a very 
low figure in comparison to many other counties and states (Schubel \& Neal, 1992). In 1993 the city collected 1,536 tons of recyclables. Savings in tipping fees from the interventions are equal to the total increase in recyclable material (Effect Size $\times 1,536$ ) multiplied by the value of the material, $\$ 15$. The estimated yearly savings for the individual feedback intervention is $\$ 5,299$, $\$ 4,378$ for group feedback, $\$ 2,534$ for information, and $\$ 3,456$ for plea only.

Combining the two sources of short-term economic gain yields a yearly savings of $\$ 28,299$ for individual feedback, $\$ 23,378$ for group feedback, $\$ 13,534$ for the information condition, and $\$ 18,456$ for the plea-only condition.

Assessment. Comparing the economic benefits of recycling with the costs for the interventions indicates that the revenue from the increase in recyclables could entirely offset the costs for the interventions - depending on the desired duration of the intervention. Comparing the citywide costs with the savings resulting from the reduction in tipping fees and value of the recycled material, cities could possibly cost effectively implement the individual feedback intervention for 14 weeks, group feedback for 16 weeks, information for 17 weeks, or the plea-only intervention for 23 weeks. The data reported in this study indicate that the two normative interventions produced an effect for at least 8 weeks, so any of these interventions could reasonably be applied successfully for their period of cost effectiveness.

These estimates are based on an extremely labor-intensive intervention procedure, and modifying the procedure could substantially reduce the labor costs and make the interventions even more cost effective. Additionally, the feedback interventions required hours of weekly observations. The method of collecting feedback data could be modified to require less labor using random sampling procedures. Also, because the group feedback and individual feedback interventions did not differ in their effect, group feedback seems preferable to individual feedback. One possible revision would be to distribute group feedback (either estimated or from the prior week) by placing the information on or in the bins at the curb when the recyclables were collected. This procedure, although untested, would sharply reduce the labor costs and help to make the interventions more economically cost effective. 


\section{CONCLUSIONS}

The results from this field experiment on interventions to improve recycling within an existing curbside program found that feedback (either group feedback or individual feedback) significantly increased the frequency of participation and amount of material recycled. None of the interventions successfully reduced the amount of contamination. The results from an assessment of the short-term economic costs and benefits of the interventions indicated that the interventions could be cost effective on a city-wide basis and could be still less costly if less labor intensive dissemination procedures were developed. Although the effectiveness of a different dissemination procedure would need to be tested, such an approach might allow cities and waste disposal companies to improve the recycling behaviors of community residents served by curbside recycling programs. The results from this study clearly indicate that normative feedback can be used successfully to alter behavior in community settings.

\section{ACKNOWLEDGMENTS}

P. Wesley Schultz is now at California State University, San M arcos.

This project was funded by a grant from the Haynes Foundation. I thank Stuart Oskamp, Dale Berger, Christina Bodinger-de Uriarte, Norm an Miller, and Lynnette Zelezny for their assistance in conceptualizing and conducting this study. Special thanks to R achel B urkha rdt and Sharri Hurin for their help in data collection and implementation of the interventions. Special thanks also to La Verne Recycling Coordinator Jeannette Vagnozzi for her assistance in producing estimates for the benefits of recycling. 


\section{REFERENCES}

California Integrated Waste Management Board. (1995). Meeting solid waste diversion mandates: A state report to the legislature. Sacramento: Author.

Cialdini, R. B., Kallgren, C. A., \& Reno, R. R. (1991). A focus theory of normative conduct: A theoretical refinement and reevaluation of the role of norms in human behavior. Advances in Experimental Social Psychology, 21, 201-234.

Cialdini, R. B., Reno, R. R.,\& Kallgren, C. A. (1990). A focus theory of normative conduct: Recycling the concept of norms to reduce littering in public places. Journal of Personality and Social Psychology, 58, 1015-1026.

DeLeon, I., \& Fuqua, R. (1995). The effects of public commitment and group feedback on curbside recycling. Environment and Behavior, 27, 233-250.

De Young, R. (1990). Recycling as appropriate behavior: A review of survey data from selected recycling education programs in Michigan. Resource Conservation and Recycling, 3, 253-267.

De Young, R., Boerschig, S., Carney, S., Dillenbeck, A., Elster, M., Horst, S., Kleiner, B, \& Thomson, B. (1995). Recycling in multi-family dwellings: Increasing participation and decreasing contamination. Population and Environment, 16, 253-268.

Dixon, R., Knott, T., Roswell, H., \& Sheldon, L. (1992). Prom pts and posted feedback: In search of an effective method of litter control. Behavior Change, 9, 2-7.

Donaldson, S. (1995). Peer influence on adolescent drug use: A perspective from the trenches of experimental evaluation research. American Psychologist, 50, 801-802.

Donaldson, S., Graham, J., Piccinin, A., \& Hansen, W. (1995). Resistance-skills training and onset of alcohol use: Evidence for beneficial and potentially harmful effects in public schools and in private Catholic schools. Health Psychology, 14, 291-300.

Environmental Protection Agency. (1988). Characterization of municipal solid waste. Washington, DC: Author.

Gardner, G., \& Stern, P. (1996). Environmental problems and human behavior. Boston: Allyn \& Bacon. 
Goldenhar, L. M., \& Connell, C. M. (1991-1992). Effects of education and feedback interventions on recycling know ledge, attitudes, beliefs, and behaviors. Journal of Environmental Systems, 21, 321-333.

Hamad, C. D., Bettinger, R., Cooper, D., \& Semb, G. (1980-1981). Using behavioral procedures to establish an elementary school paper recycling program. Journal of Environmental Systems, 10, 149-156.

Katzev, R. D., \& Mishima, H. (1992). The use of posted feedback to promote recycling. Psychological Reports, 71, 259-264.

Keppel, G., \& Zedeck, S. (1989). Data analysis for research designs: Analysis of variance and multiple regression/correlation approaches. New York: Freeman.

Kluger, A ., \& De Nisi, A. (19 96). The effects of feedback interventions on performance: A historical review , a meta-analysis, and a preliminary feedback intervention theory. Psychological Bulletin, 1 19, 254 -28 4.

Leeming, F., Dwyer, W., Porter, B., \& Cobern, M. (1993). Outcome research in environmental education: A critical review. Journal of Environmental Education, 24, 8-21.

Locke, E. A., \& Latham, G. P. (1990). A theory of goal setting and task performance. Englewood Cliffs, NJ: Prentice Hall.

Oskamp, S., Burkhardt, R., Schultz, P., Hurin, S., \& Zelezny, L. (1998). Predicting three dimensions of residential curbside recycling: An observational study. Journal of Environmental Education, 29, 37-42.

Oskamp, S., Zelezny, L., Schultz, P. W., Hurin, S., \& Burkhardt, R. (1996). Commingled versus separated recycling: Does sorting matter? Environment and Behavior, 28, 73-91.

Pedhazur, E. J. (1997). Multiple regression in behavioral research: Explanation and prediction (3rd ed.). Fort Worth, TX: Harcourt Brace.

Porter, B., Leeming, F., \& Dwyer, W . (1995). Solid waste recovery: A review of behavioral programs to increase recycling. Environment and Behavior, 27, 122152.

Reno, R. R., Cialdini, R. B., \& Kallgren, C. A. (1993). The trans-situational influence of norms. Journal of Personality and Social Psychology, 64, 104-112.

Schubel, J. R., \& Neal, H. A. (1992). Garbage and trash: Can we convert mountains unto molehills? Stony Brook: Research Foundation, State 
University of New York at Stony Brook.

Schultz, P. W., Oskamp, S., \& Mainieri, T. (1995). Who recycles and when? A review of personal and situational factors. Journal of Environmental Psychology, 15, 105-121.

Schwartz, S. H., \& Fleishman, J. A. (1978). Personal norms and the mediation of legitimacy effects on helping. Social Psychology, 41, 306-315. 